\title{
Effect of Thermal Treatment on the Electrocatalytic Activities and Surface Roughness of ITO Electrodes
}

\author{
Moonjeong Choi, Kyungmin Jo, and Haesik Yang ${ }^{\dagger}$ \\ Department of Chemistry and Chemistry Institute of Functional Materials, Pusan National University, Busan 609-735, \\ Republic of Korea
}

\begin{abstract}
:
The electrocatalytic activities and surface roughness of indium-tin-oxide (ITO) electrodes have been investigated after thermal treatment at 100,150 , or $200^{\circ} \mathrm{C}$ for $30 \mathrm{~min}, 2 \mathrm{~h}$, or $8 \mathrm{~h}$. To check electrocatalytic activities, the electrochemical behavior of four electroactive species ( $p$-hydroquinone, $\mathrm{Ru}\left(\mathrm{NH}_{3}\right)_{6}{ }^{3+}$, ferrocenemethanol, and $\mathrm{Fe}(\mathrm{CN})_{6}{ }^{4}$ ) has been measured. The electron transfer rate for $p$-hydroquinone oxidation and ferrocenemethanol oxidation increases with increasing the incubation temperature and the incubation period of time, but the rate for $\mathrm{Ru}\left(\mathrm{NH}_{3}\right)_{6}{ }^{3+}$ is similar irrespective of the incubation temperature and period because $\mathrm{Ru}\left(\mathrm{NH}_{3}\right)_{6}{ }^{3+}$ undergoes a fast outer-sphere reaction. Overall, the electrocatalytic activities of ITO electrodes increase with increasing the incubation temperature and period. The surface roughness of ITO electrodes increases with increasing the incubation temperature, and the thermal treatment generates many towering pillars as high as several tens of nanometer.
\end{abstract}

Keywords : Indium-tin-oxide electrode, Thermal treatment, Electrocatalytic activity, $p$-hydroquinone, $\mathrm{Ru}\left(\mathrm{NH}_{3}\right)_{6}{ }^{3+}$, ferrocenemethanol, $\mathrm{Fe}(\mathrm{CN})_{6}{ }^{4-}$

Received February 6, 2012 : Accepted March 2, 2012

\section{Introduction}

Indium-tin-oxide (ITO) electrodes have been widely used as conducting electrodes or substrates in electrochemical sensors, solar cells, and displays. ${ }^{1-3)}$ Low and reproducible capacitive background currents, moderately low electrocatalytic activities, and wide potential windows of ITO electrodes facilitate us to achieve high signal-to-background ratios in electrochemical sensors. ${ }^{1,2,4,5)}$ Good electric conductivity, chemical inertness, and mechanical robustness of ITO electrodes are also beneficial for sensitive and reproducible electrochemical sensors.

The type of electrode materials plays a dominant role in determining their electrocatalytic activities. For

${ }^{\dagger}$ Corresponding author. Tel.: +82-51-510-3681

E-mail address: hyang@pusan.ac.kr example, Pt electrodes show high electrocatalytic activities for most electrochemical reactions, whereas ITO electrodes show much lower electrocatalytic activities. In many cases, however, it is required to tune intrinsic electrocatalytic activities without modifying the electrodes with electrocatalytic or insulating materials. In general, this fine-tuning has been carried out via thermal, chemical, or electrochemical treatment of electrodes. ${ }^{6-11)}$ Although many treatment methods for the fine-tuning of metal electrodes, ${ }^{6-11}$ ) carbon-based electrodes, ${ }^{12)}$ and boron-doped diamond electrodes ${ }^{13)}$ have been developed, those of ITO electrodes have been far less studied. ${ }^{14)}$ In particular, there is no report for tuning the electrocatalytic activities of ITO electrodes via thermal treatment.

The modification of ITO electrodes with silane or phosphonate self-assembled monolayers requires elevation of temperature. ${ }^{15)}$ The monolayers are com- 
monly employed to introduce functional groups or change surface properties. The thermal treatment may change surface roughness of ITO electrodes. It is also important to know how temperature affects surface roughness.

In this study, the change in electrocatalytic activity and surface roughness of ITO electrodes has been investigated after thermal treatment. The electrocatalytic activities of ITO electrodes toward $p$-hydroquinone, $\mathrm{Ru}\left(\mathrm{NH}_{3}\right)_{6}{ }^{3+}$, ferrocenemethanol, and $\mathrm{Fe}(\mathrm{CN})_{6}{ }^{4-}$ have been measured and their atomic force microscopy (AFM) images were obtained after the electrodes were incubated at 100,150 , or $200^{\circ} \mathrm{C}$ for $30 \mathrm{~min}, 2 \mathrm{~h}$, or $8 \mathrm{~h}$.

\section{Experimental}

ITO-coated glasses were obtained from Samsung Corning (Daegu, Korea). ITO electrodes were cleaned under ultrasonication in dichloromethane and then in methanol for $10 \mathrm{~min}$, followed by treatment with $0.5 \mathrm{M} \mathrm{K}_{2} \mathrm{CO}_{3}$ in a 3:1 mixture of methanol and water for $30 \mathrm{~min}$ under ultrasonication to remove any residual organic contaminants. ITO electrodes were then rinsed with copious amounts of water. Thermal treatment of ITO electrodes was performed in a convection drying oven.

All chemicals were purchased from Sigma-Aldrich and used without further purification. Phosphatebuffered saline (PBS) solutions consisted of $0.01 \mathrm{M}$ phosphate, $0.138 \mathrm{M} \mathrm{NaCl}$, and $0.0027 \mathrm{M} \mathrm{KCl}$ (pH 7.4).

The electrochemical experiments were performed using a $\mathrm{CHI} 405 \mathrm{~A}$ instrument (CH instruments, Austin, TX, USA) and an electrochemical cell consisting of an ITO working electrode, a Pt counter electrode, and an $\mathrm{Ag} / \mathrm{AgCl}(3 \mathrm{M} \mathrm{NaCl})$ reference electrode at room temperature. AFM images were obtained using an XE-100 (Park System, Korea), operated in noncontact mode.

\section{Results and discussion}

In order to investigate electrocatalytic activities of ITO electrodes, four electrochemical reactions were investigated before and after thermal treatment.
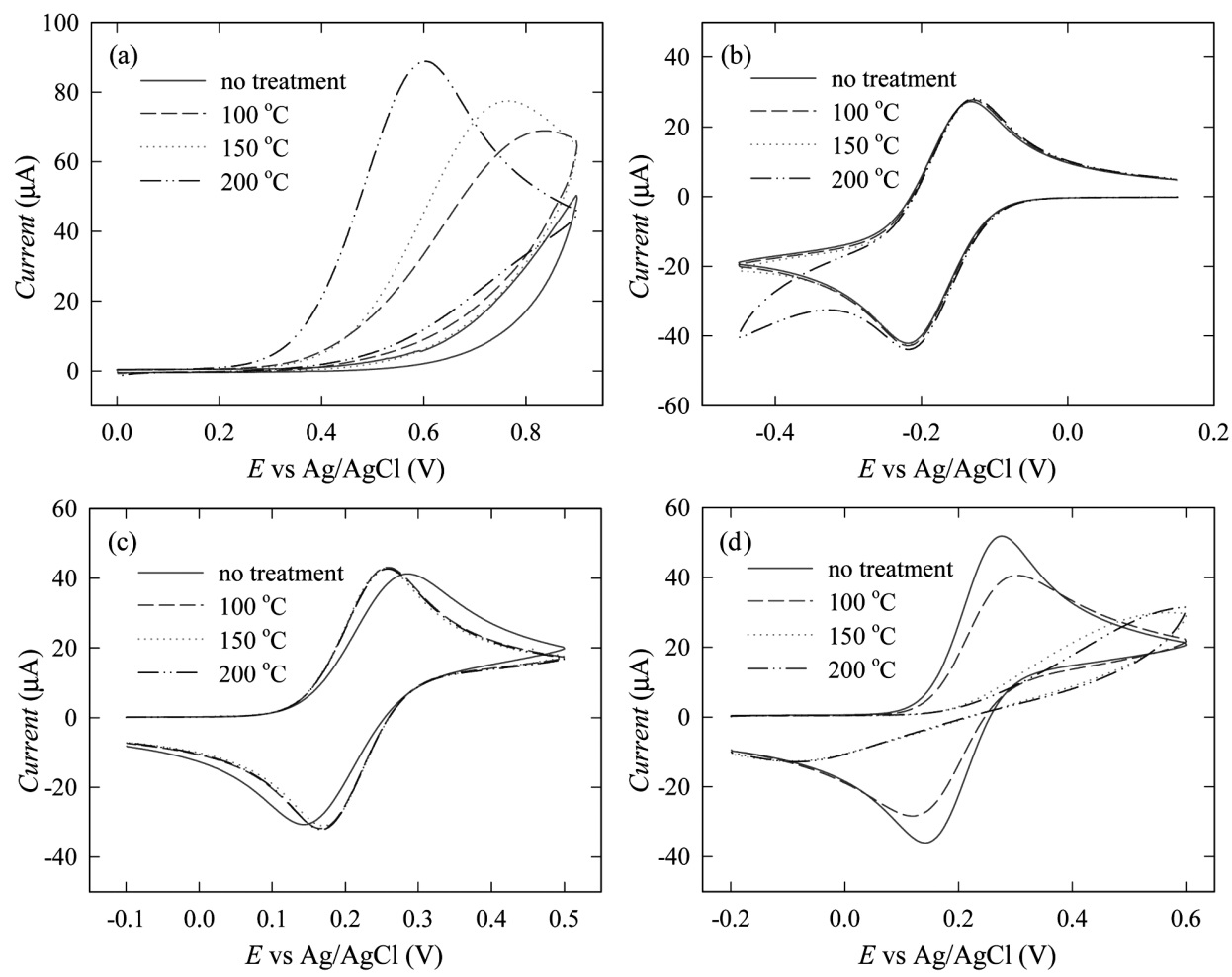

Fig. 1. Cyclic voltammograms obtained (at a scan rate of $50 \mathrm{mV} / \mathrm{s}$ ) in $\mathrm{PBS}(\mathrm{pH} 7.4$ ) containing (a) $1.0 \mathrm{mM}$-hydroquinone, (b) $\mathrm{Ru}\left(\mathrm{NH}_{3}\right)_{6}{ }^{3+}$, (c) ferrocenemethanol, or (d) Fe(CN) ${ }_{6}{ }^{4-}$ at ITO electrodes after the incubation at 100,150 , or $200^{\circ} \mathrm{C}$ for $8 \mathrm{~h}$. 
Fig. 1 shows cyclic voltammograms for $p$-hydroquinone, $\mathrm{Ru}\left(\mathrm{NH}_{3}\right)_{6}{ }^{3+}$, ferrocenemethanol, and $\mathrm{Fe}(\mathrm{CN})_{6}{ }^{4-}$ observed in PBS buffer. As the electrochemical behavior of $p$-hydroquinone highly depends on the electrocatalytic activity of an electrode, ${ }^{16)}$ $p$-hydroquinone was selected for the evaluation of the electrocatalytic activity. In Fig. 1(a), the incubation at
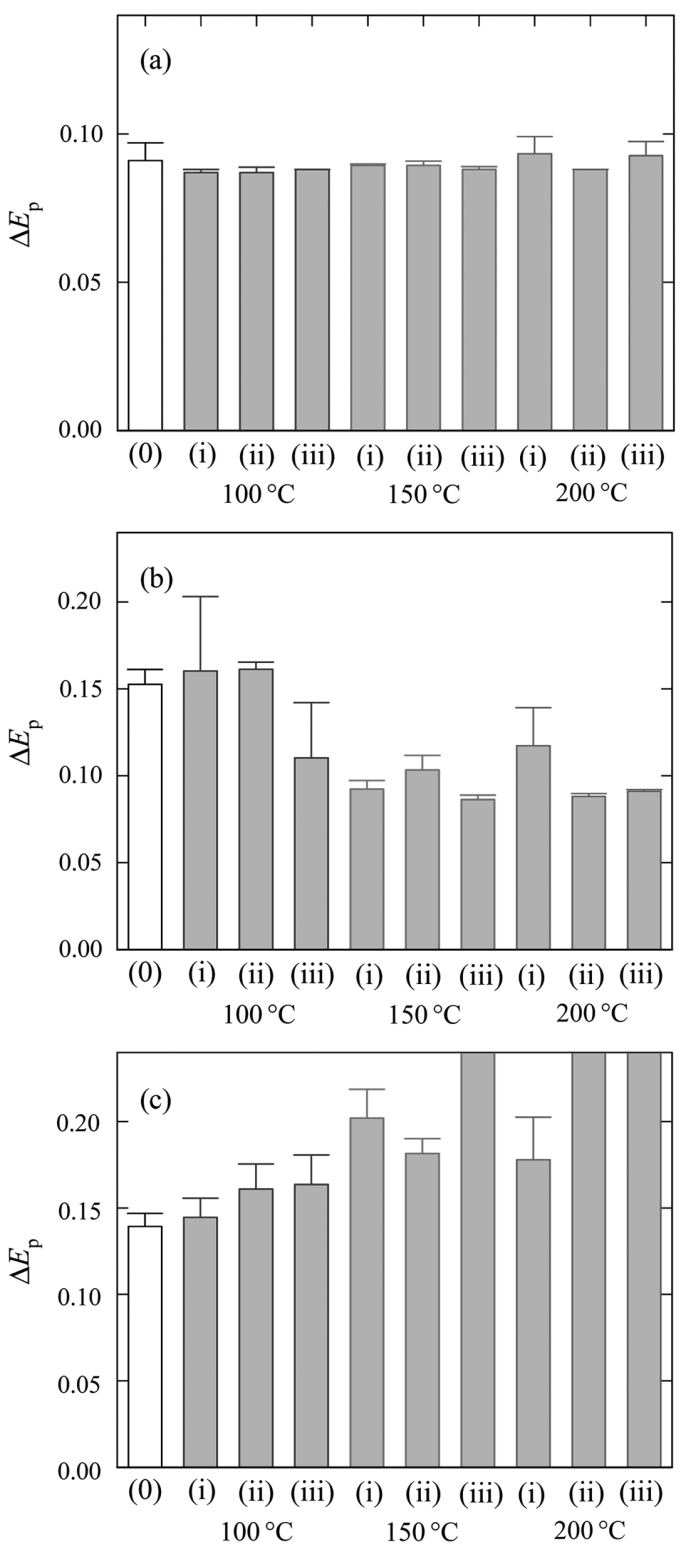

Fig. 2. $\Delta E_{\mathrm{p}}$ in cyclic voltammograms obtained (at a scar rate of $50 \mathrm{mV} / \mathrm{s}$ ) in PBS (pH 7.4) containing (a $\mathrm{Ru}\left(\mathrm{NH}_{3}\right)_{6}{ }^{3+}$, (b) ferrocenemethanol, or (c) $\mathrm{Fe}(\mathrm{CN})_{6}{ }^{4-}$ at ITC electrodes $(0)$ before and (i, ii, iii) after the incubation a 100,150 , or $200{ }^{\circ} \mathrm{C}$ for (i) $30 \mathrm{~min}$, (ii) $2 \mathrm{~h}$, or (iii) $8 \mathrm{~h}$.
100,150 , and $200^{\circ} \mathrm{C}$ for $8 \mathrm{~h}$ allowed the oxidation of $p$-hydroquinone to start from lower potentials. The incubation at $200^{\circ} \mathrm{C}$ gave a high anodic peak around $0.6 \mathrm{~V}$ and significantly decreased the overpotential for the oxidation of $p$-hydroquinone. The results clearly indicate that the thermal treatment of ITO electrodes increases their electrocatalytic activities toward $p$-hydroquinone oxidation.

It is well known that $\mathrm{Ru}\left(\mathrm{NH}_{3}\right)_{6}{ }^{3+}$ can undergo a fast outer-sphere reaction at high reaction rates. ${ }^{17)}$ In this case, the voltammetric behaviors should be independent of the electrocatalytic activities of electrodes. In Fig. 1(b), anodic (and cathodic) peak currents and potentials in the cyclic voltammograms of $\mathrm{Ru}\left(\mathrm{NH}_{3}\right)_{6}{ }^{3+}$ were similar irrespective of the incubation temperature, and they were almost the same as those obtained without thermal treatment. In Fig. 2(a), the difference between anodic peak and cathodic peak $\left(\Delta E_{\mathrm{p}}\right)$ in the cyclic voltammogram of $\mathrm{Ru}\left(\mathrm{NH}_{3}\right)_{6}{ }^{3+}$ was also independent of the incubation period of time. It is interesting to note that cathodic currents (at potentials more negative than $-0.2 \mathrm{~V}$ ) obtained after the incubation at $200^{\circ} \mathrm{C}$ were much higher than others (Fig. 1(b)). The higher cathodic currents are due to the electroreduction of oxygen dissolved in solution. It also shows that thermal treatment increases the electrocatalytic activities of ITO electrodes.

On the other hand, the voltammetric behavior of ferrocenemethanol depended on the incubation temperature (Fig. 1(c)). $\Delta E_{\mathrm{p}}$ decreased with increasing the incubation temperature and the incubation period of time (Fig. 2(b)). The electrocatalytic activities of ITO

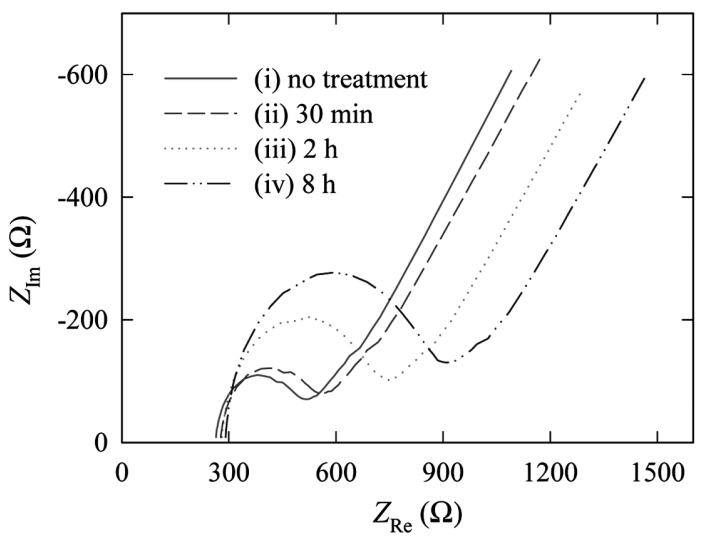

Fig. 3. Impedance data obtained at $0.2 \mathrm{~V}$ in $\mathrm{PBS}$ containing $1.0 \mathrm{mM} \mathrm{Fe}(\mathrm{CN})_{6}{ }^{4-}$ and $1.0 \mathrm{mM} \mathrm{Fe}(\mathrm{CN})_{6}{ }^{3-}$ at ITO electrodes after the incubation at $100{ }^{\circ} \mathrm{C}$ for $30 \mathrm{~min}, 2$ $\mathrm{h}$, or $8 \mathrm{~h}$. 

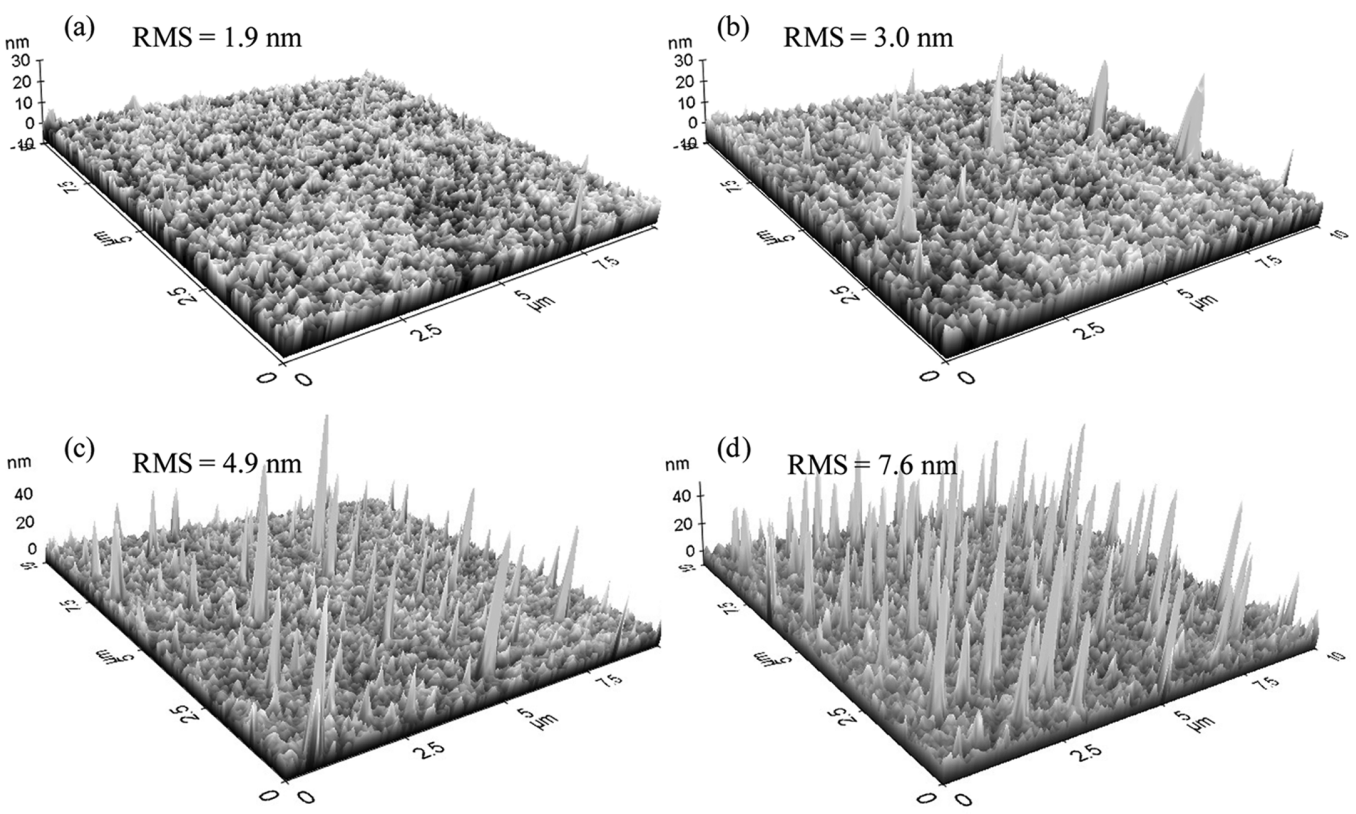

Fig. 4. AFM images of ITO electrodes obtained (a) before and (b, c, d) after the incubation at (b) 100 , (c) 150 , or (d) $200^{\circ} \mathrm{C}$ for $8 \mathrm{~h}$.

electrodes for ferrocenemethanol may increase with increasing the incubation temperature and the incubation period of time. It seems that the interaction between ferrocenemethanol and ITO electrode affects electron transfer rate.

Interestingly, in the case of $\mathrm{Fe}(\mathrm{CN})_{6}{ }^{4-}, \Delta E_{\mathrm{p}}$ increased with increasing the incubation temperature and the incubation period of time (Fig. 1(d) and 2(c)). In general, the electrochemical behavior of $\mathrm{Fe}(\mathrm{CN})_{6}{ }^{4-}$ is surface-sensitive and highly sensitive to electrostatic repulsion because of its high negative charge. ${ }^{17,18)}$ When impedance data were obtained in a solution containing $\mathrm{Fe}(\mathrm{CN})_{6}{ }^{4-}$ and $\mathrm{Fe}(\mathrm{CN})_{6}{ }^{3-}$, the size of semicircle related to charge transfer resistance increased with the incubation time at $100^{\circ} \mathrm{C}$ (Fig. 3). It seems that the increase in $\Delta E_{\mathrm{p}}$ is related to the change in surface state.

To investigate the change in surface roughness after thermal treatment, AFM images were obtained (Fig. 4). The images clearly show that the surface roughness of ITO electrodes increased with increasing the incubation temperature. The image obtained after the incubation at $200^{\circ} \mathrm{C}$ contained many towering pillars (Fig. 3(d)), although the image for an untreated ITO electrode did not (Fig. 4(a)). The pillars were as high as several tens of nanometer. Root- square-mean (RMS) value was $1.9 \mathrm{~nm}$ before thermal treatment, but it was increased to 3.0, 4.9, and $7.6 \mathrm{~nm}$ after the incubation at 100,150 , and $200^{\circ} \mathrm{C}$, respectively. All results show that the thermal treatment of ITO electrodes significantly increases their surface roughness.

\section{Conclusions}

We have investigated the electrocatalytic activities and surface roughness of ITO electrodes after thermal treatment. The electrocatalytic activities of ITO electrodes increase with increasing the incubation temperature and period. However, the electron transfer rate for $\mathrm{Ru}\left(\mathrm{NH}_{3}\right)_{6}{ }^{3+}$ was independent of the incubation temperature and period because $\mathrm{Ru}\left(\mathrm{NH}_{3}\right)_{6}{ }^{3+}$ undergoes a fast outer-sphere reaction, and the rate for $\mathrm{Fe}(\mathrm{CN})_{6}{ }^{4-}$ decreased after thermal treatment because $\mathrm{Fe}(\mathrm{CN})_{6}{ }^{4-}$ is surface-sensitive. The surface roughness of ITO electrodes significantly increased with increasing the incubation temperature.

\section{Acknowledgments}

This study was supported by the Basic Science Research Program (2009-0072062 and 2009- 
0085182) through the National Research Foundation of Korea (NRF) funded by the Ministry of Education, Science and Technology.

\section{References}

1. J. Das, K. Jo, J. W. Lee and H. Yang, Anal. Chem., 79, 2790 (2007).

2. M. R. Akanda, Y.-L. Choe and H. Yang, Anal. Chem., 84, 1049 (2012)

3. H.-Y. Liu, V. Avrutin, N. Izyumskaya, U. Ozgur and H. Morkoc, Superlatt. Microstruc., 48, 458 (2010).

4. A. N. Asanov, W. W. Wilson and P. B. Oldham, Anal. Chem., 70, 1156 (1998).

5. I. Zudans, J. R. Paddock, H. Kuramitz, A. T. Maghasi, C. M. Wansapura, S. D. Conklin, N. Kaval, T. Shtoyko, D. J. Monk, S. A. Bryan, T. L. Hubler, J. N. Richardson, C. J. Seliskar and W. R. Heineman, J. Electroanal. Chem., 565, 311 (2004).

6. S.-G. Sun, W.-B. Cai, L.-J. Wan and M. Osawa, J. Phys. Chem. B, 103, 2460 (1999).

7. L. D. Burke, L. M. Hurley, V. E. Lodge and M. B. Mooney, J. Solid State Electrochem., 5, 250 (2001).
8. N. V. Krstajic, L. M. Vracar, V. R. Radmilovic, S. G. Neophytides, M. Labou, J. M. Jaksic, R. Tunold, P. Falaras and M. M. Jaksic, Surf. Sci., 601, 1949 (2007).

9. R. C. Orellana, M. E. Martins and A. J. Arvía, Electrochim. Acta, 24, 469 (1979).

10. V. Bhalla, S. Carrara, C. Stagni and B. Samorì, Thin Solid Films, 518, 3360 (2010).

11. J. Kang and P. A. Rowntree, Langmuir, 23, 509 (2007).

12. R. L. McCreery, Chem. Rev., 108, 2646 (2008).

13. M. Panizza and G. Cerisola, Electrochim. Acta, 51, 191 (2005).

14. S. Gardonio, L. Gregoratti, D. Scaini, C. CastellarinCudia, P. Dudin, P. Melpignano, V. Biondo, R. Zamboni, S. Caria and M. Kiskinova, Org. Electron., 9, 253 (2008).

15. C. Haensch, S. Hoeppener and U. S. Schubert, Chem. Soc. Rev. 39, 2323 (2010).

16. A. M. Nowicka, U. Hasse, G. Sievers, M. Donten, Z. Stojek, S. Fletcher and F. Scholz, Angew. Chem. Int. Ed., 49, 3006 (2010)

17. P. Chen and R. L. McCreery, Anal. Chem., 68, 3958 (1996).

18. K. Jo, H.-Z. Yu and H. Yang, Electrochim. Acta, 56, 4828 (2011). 